\title{
Risk factors for lymph node metastasis and surgical methods in patients with early- stage peripheral lung adenocarcinoma presenting as ground glass opacity
}

Yongming Wang ${ }^{1,2+}$, Lijun Jing ${ }^{3+}$ and Gongchao Wang ${ }^{1 *}$

\begin{abstract}
Background: It is difficult to predict lymph node metastasis in patients with early lung cancer. Pure ground glass opacity (GGO) on computed tomography indicates an early-stage adenocarcinoma that can be removed by limited resection or lobectomy without the need for mediastinal lymph node dissection or sampling, and lung adenocarcinoma with GGO therefore has a good prognosis. We examined the incidence and risk factors of lymph node metastasis in patients with clinical stage IA lung adenocarcinoma.

Methods: We retrospectively analyzed clinical data for 327 patients with stage IA peripheral lung cancer treated in our hospital from March 2014 to December 2018. The patients were divided into four groups according to computed tomography signs. Lobectomy and systematic lymph node dissection were performed in all patients. Correlations between lymph node metastasis and clinical pathological factors were analyzed by logistic regression.

Results: Among the 327 patients, 26 (7.95\%) had lymph node metastasis. No patients with pure GGO or GGOdominant types had lymph node metastasis. Logistic regression identified tumor diameter, solid content, plasma carcinoembryonic antigen (CEA) level, pathological type, lymphovascular invasion, and pleural invasion as factors related to the presence of lymph node metastasis.

Conclusions: Tumor diameter, solid component ratio, plasma CEA level, pathological type, vascular tumor thrombus, and pleural invasion are possible independent risk factors for lymph node metastasis in patients with stage IA lung adenocarcinoma. In contrast, lymph node metastasis is rare in patients with pure GGO or GGOdominant lung adenocarcinoma.
\end{abstract}

Keywords: Lung adenocarcinoma, Ground glass nodule, Lymph node metastasis

\footnotetext{
* Correspondence: wanggongchao@126.com

†Yongming Wang and Lijun Jing contributed equally to this work.

'Department of Thoracic Surgery, Shandong Provincial Hospital, Cheeloo College of Medicine, Shandong University, Jinan 250021, Shandong, China Full list of author information is available at the end of the article
}

(c) The Author(s). 2020 Open Access This article is licensed under a Creative Commons Attribution 4.0 International License, which permits use, sharing, adaptation, distribution and reproduction in any medium or format, as long as you give appropriate credit to the original author(s) and the source, provide a link to the Creative Commons licence, and indicate if changes were made. The images or other third party material in this article are included in the article's Creative Commons licence, unless indicated otherwise in a credit line to the material. If material is not included in the article's Creative Commons licence and your intended use is not permitted by statutory regulation or exceeds the permitted use, you will need to obtain permission directly from the copyright holder. To view a copy of this licence, visit http://creativecommons.org/licenses/by/4.0/ The Creative Commons Public Domain Dedication waiver (http://creativecommons.org/publicdomain/zero/1.0/) applies to the data made available in this article, unless otherwise stated in a credit line to the data. 


\section{Background}

Lung cancer is the main cause of cancer-related death [1]. However, although the 5-year survival rate of lung cancer is only $15 \%$, this can be increased to about $50 \%$ by the timely diagnosis and treatment of early-stage lung cancer [2]. Lung adenocarcinoma is the most common type of lung cancer, accounting for more than $50 \%$ of non-small cell lung cancers, and the percentage is continuing to increase [3].

Progress in computed tomography (CT) has led to an increase in the detection rate of early lung nodules, including many early lung cancers [4], with relatively low malignancy and a good postoperative prognosis. Lung nodules can be divided into the following categories according to the ground glass opacity (GGO) findings: pure GGO (PGGO), mixed GGO (MGGO) or partial-solid GGO, and solid GGO (SGGO).

Compared with the seventh edition, the eighth edition of the TNM staging of lung cancer divided T1a into T1a and $\mathrm{T} 1 \mathrm{~b}$, and changed the original $\mathrm{T} 1 \mathrm{~b}$ to the new $\mathrm{T} 1 \mathrm{c}$ as follows: T1a $(\leq 1 \mathrm{~cm})$, T1b $(>1$ to $\leq 2 \mathrm{~cm})$, and T1c (> 2 to $\leq 3 \mathrm{~cm}$ ) [5]. In 2011, the International Association for Lung Cancer Research, the American Thoracic Society, and the European Respiratory Society jointly issued a new international multi-disciplinary classification standard for lung cancer [6]. The incidence of lymph node metastasis in patients with lung cancer with GGO is currently unclear, and the need for lymph node cleaning during surgery is controversial. In this study, we retrospectively examined the incidence and risk factors of lymph node metastasis in patients with clinical stage IA peripheral lung adenocarcinoma with GGO findings, with the aim of providing evidence for future clinical applications.

\section{Methods}

We retrospectively analyzed the clinical data for 516 patients who underwent surgical resection at the Department of Thoracic Surgery, Weifang NO.2 People's Hospital, shandong, China, from March 2014 to December 2018.

All patients underwent routine pulmonary function examination, craniocerebral magnetic resonance imaging or CT, systematic bone scan, abdominal ultrasound or $\mathrm{CT}$ to exclude possible metastases, and analysis of related tumor markers. After plain or enhanced CT scans, all images were transferred to an AW4.6 workstation (GE Healthcare, Chicago, IL, USA) for post-processing. Hilar and mediastinal nodes were considered positive if the short axis was $>1 \mathrm{~cm}$ on chest CT images.

The inclusion criteria were as follows: (1) GGO lesions confirmed by high-resolution CT; (2) histopathologically confirmed adenocarcinoma; (3) systematic lymph node dissection that met the current standards (i.e. all lymph node stations 2-4 and 7-12 on the right side and stations 4-12 on the left side, according to the American Thoracic Society classification); and (4) tumor diameter $\leq 3 \mathrm{~cm}$. Exclusion criteria were as follows: (1) preoperative distant metastasis with a history of lung cancer or new adjuvant chemotherapy; (2) cardiopulmonary function not suitable for segmentectomy or lobectomy; (3) patients with multiple lesions;and (4) no systematic lymph node dissection. There were 327 eligible patients.

Patients were divided into four groups according to the extent of the radiologic findings of GGO on preoperative chest $\mathrm{CT}$. The consolidation/tumor ratio $(\mathrm{C} / \mathrm{T}) \%$ was defined as the proportion of the maximum consolidation diameter divided by the maximum tumor diameter. Four groups were defined as follows: PGGO, GGO-dominant type $(\mathrm{C} / \mathrm{T} \leq 0.5)$, solid component dominant type $(\mathrm{C} / \mathrm{T}>0.5$ to $<1)$, and solid tumor.

All patients underwent complete thoracoscopic surgery, with no transthoracic surgery or secondary surgery. For peripheral nodules, partial lobectomy (wedge resection or segmentectomy) was performed and the sample was then sent for frozen sectioning. If the frozen-pathology results indicated adenocarcinoma in situ or microinvasive adenocarcinoma, systemic lymph node dissection was performed, but in the case of invasive adenocarcinoma, lobectomy and systemic lymph node dissection were performed. Deep nodules were treated initially with segmentectomy or lobectomy, followed by systemic lymph node dissection. In our department, systematic lymph node dissection is required to include stations $2-4$ and $7-12$ in the right lung and 4-12 in the left lung.

\section{Statistical analysis}

All the data were analyzed using SPSS 18.0 statistical software. Risk factors for lymph node metastasis were analyzed by $t$-tests, $X^{2}$ tests, and logistic regression. A value of $P<0.05$ was considered significant.

\section{Results}

Clinical data for the 327 patients are presented in Table 1. Twenty-six patients (7.95\%) had mediastinal lymph node metastasis, including 10 (3.1\%) with only N1 lymph node metastasis, five (1.5\%) with only skip N2 metastatic lymph nodes with no $\mathrm{N} 1$ positive nodes, and 11 patients (3.4\%) with both N1 and N2 lymph node metastasis. No mediastinal lymph node metastasis was present in the PGGO and GGO groups, while nine patients (9/120) with solid component dominant type and 17 (17/114) with pure solid tumor type had mediastinal lymph node metastasis.

Univariate analysis showed that age, smoking history, tumor location, and operation type were not correlated with lymph node metastasis, but sex, tumor diameter, 
Table 1 Clinicopathologic characteristics

\begin{tabular}{|c|c|c|c|c|c|}
\hline Variable & Total & $\mathrm{pNO}$ & $\mathrm{pN} 1+\mathrm{N} 2$ & $\times 2$ & $P$ value \\
\hline All patients & 327 & 301 & 26 & & \\
\hline Age (years) & & & & 2.264 & 0.322 \\
\hline$\geq 60$ & 172 & 162 & 10 & & \\
\hline$<60$ & 155 & 139 & 16 & & \\
\hline Gender & & & & 5.663 & 0.017 \\
\hline Male & 121 & 117 & 4 & & \\
\hline Female & 206 & 184 & 22 & & \\
\hline Smoking history & & & & 1.593 & 0.207 \\
\hline Present & 139 & 131 & 8 & & \\
\hline Absent & 188 & 170 & 18 & & \\
\hline Tumor size $(\mathrm{cm})$ & & & & 29.986 & 0.000 \\
\hline$<1.0$ & 79 & 79 & 0 & & \\
\hline $1.1-2.0$ & 140 & 135 & 5 & & \\
\hline $2.1-3.0$ & 108 & 87 & 21 & & \\
\hline Consolidation tumor ratio(C) & & & & 14.676 & 0.001 \\
\hline 0 & 43 & 43 & 0 & & \\
\hline 0 to $\leq 0.5$ & 50 & 50 & 0 & & \\
\hline 0.5 to $<1$ & 120 & 111 & 9 & & \\
\hline 1 & 114 & 97 & 17 & & \\
\hline CEA level (ng/mL) & & & & 5.246 & 0.022 \\
\hline$\leq 5$ & 268 & 251 & 17 & & \\
\hline$>5$ & 59 & 50 & 9 & & \\
\hline Tumor location & & & & 0.569 & 0.966 \\
\hline Right upper lobe & 102 & 95 & 7 & & \\
\hline Right middle lobe & 31 & 28 & 3 & & \\
\hline Right lower lobe & 53 & 49 & 4 & & \\
\hline Left upper lobe & 79 & 73 & 6 & & \\
\hline Left lower lobe & 62 & 56 & 6 & & \\
\hline Operations type & & & & 5.560 & 0.062 \\
\hline Wedge & 29 & 29 & 0 & & \\
\hline Segmentectomy & 43 & 42 & 1 & & \\
\hline Lobectomy & 255 & 230 & 25 & & \\
\hline Pathologic type & & & & 10.407 & 0.004 \\
\hline AIS & 31 & 31 & 0 & & \\
\hline MIA & 52 & 52 & 0 & & \\
\hline IA & 244 & 218 & 26 & & \\
\hline Lymphovascular invasion & & & & 53.189 & 0.000 \\
\hline Present & 51 & 34 & 17 & & \\
\hline Absent & 276 & 267 & 9 & & \\
\hline Pleural invasion & & & & 44.469 & 0.000 \\
\hline Present & 46 & 31 & 15 & & \\
\hline Absent & 281 & 270 & 11 & & \\
\hline
\end{tabular}

PGGO pure ground-glass opacity, AIS adenocarcinoma in situ, MIA minimally invasive adenocarcinoma, $I A$ invasive adenocarcinoma.
Table 2 Assignment description of influencing factors

\begin{tabular}{|c|c|}
\hline Influencing factor & Assignment description \\
\hline Gender & Man $=1$, Female $=2$ \\
\hline Age (year) & $<60=1, \geq 60=2$ \\
\hline Smoking history & $\mathrm{No}=0, \mathrm{YES}=1$ \\
\hline Tumor size $(\mathrm{cm})$ & $<1.0=1,1.0-2.0=2,2.1-3.0=3$ \\
\hline \multicolumn{2}{|c|}{ Consolidation tumor ratio(C/T) } \\
\hline PGGO & $\mathrm{No}=0, \mathrm{YES}=1$ \\
\hline GGO-predominant & $\mathrm{No}=0, \mathrm{YES}=1$ \\
\hline Solid-predominant & $\mathrm{No}=0, \mathrm{YES}=1$ \\
\hline Solid & $\mathrm{No}=0, \mathrm{YES}=1$ \\
\hline Serum CEA (ng/ml) & $\leq 5=1,>5=2$ \\
\hline \multicolumn{2}{|l|}{ Tumor location } \\
\hline Right upper lobe & $\mathrm{No}=0, \mathrm{YES}=1$ \\
\hline Right middle lobe & $\mathrm{No}=0, \mathrm{YES}=1$ \\
\hline Right lower lobe & $\mathrm{No}=0, \mathrm{YES}=1$ \\
\hline Left upper lobe & $\mathrm{No}=0, \mathrm{YES}=1$ \\
\hline Left lower lobe & $\mathrm{No}=0, \mathrm{YES}=1$ \\
\hline \multicolumn{2}{|l|}{ Operations type } \\
\hline Wedge & $\mathrm{No}=0, \mathrm{YES}=1$ \\
\hline Segmentectomy & $\mathrm{No}=0, \mathrm{YES}=1$ \\
\hline Lobectomy & $\mathrm{No}=0, \mathrm{YES}=1$ \\
\hline \multicolumn{2}{|l|}{ Pathological type } \\
\hline AIS & $\mathrm{No}=0, \mathrm{YES}=1$ \\
\hline MIA & $\mathrm{No}=0, \mathrm{YES}=1$ \\
\hline IMA & $\mathrm{No}=0, \mathrm{YES}=1$ \\
\hline Visceral invasion & $\mathrm{No}=0, \mathrm{YES}=1$ \\
\hline Pleural invasion & $\mathrm{No}=0, \mathrm{YES}=1$ \\
\hline
\end{tabular}

solid composition, plasma carcinoembryonic antigen (CEA) level, pathological type, vascular tumor thrombus, and pleural invasion were all related to lymph node metastasis.

Taking lymph node metastasis as a dependent variable with metastasis assignment as 1 and non-metastasis assignment as 0 (Table 2), we conducted multivariate unconditional binary logistic regression analysis (SLE $=$ 0.05 , SLS $=0.10$ ) with age, sex, smoking history, tumor size, consolidation tumor ratio, CEA level, pathologic type, lymphovascular invasion, and pleural invasion as independent variables.

The results identified tumor diameter, proportion of solid components, plasma CEA level, pathological type, vascular tumor thrombus, and pleural invasion as risk factors for lymph node metastasis (Table 3).

\section{Discussion}

The TNM staging standard for lung cancer was revised by the International Association for Lung Cancer 
Table $\mathbf{3}$ Independent predictors of lymph node metastasis by multivariate analysis

\begin{tabular}{llll}
\hline Variables & HR & $95 \% \mathrm{Cl}$ & $\mathrm{P}$ value \\
\hline Tumor size & 1.503 & $1.155-1.955$ & 0.002 \\
Serum CEA & 1.574 & $1.217-2.036$ & 0.001 \\
Pathological type & 3.515 & $1.027-12.033$ & 0.042 \\
Visceral invasion & 2.913 & $2.046-4.146$ & 0.000 \\
Pleural invasion & 2.099 & $1.513-2.911$ & 0.000 \\
\hline
\end{tabular}

$H R$ hazard ratio, $\mathrm{Cl}$ confidence interval.

Research, with the new version reflecting the prognostic importance of tumor diameter. Previous studies found that tumor diameter was positively correlated with lymph node metastasis. A previous study in China [7] found mediastinal lymph node metastasis rates of 0 , 10.5 , and $29.7 \%$ in patients with peripheral lung cancers with diameters of $0-1,1-2$, and $2-3 \mathrm{~cm}$, respectively $(P=0.003)$, while Okada et al. [8] reported that the rate of lymph node metastasis increased as the tumor size increased. The current study found similar results.

Previous studies found that the proportion of solid components in pulmonary nodules was related to lymph node metastasis. Matsuguma et al. [9] divided pulmonary nodules into five grades according to the proportion of solid components and showed that solid components were an independent risk factor for lymph node metastasis, i.e., the higher the proportion of solid components, the stronger the invasiveness of the lung cancer. Chen et al. [10] conducted a retrospective analysis of 867 patients with stage T1 lung cancer and divided them into three groups according to the proportion of solid components: I (pure GGO, $n=553)$, II $(1-50 \%, n=160)$, and III $(50-79 \%, n=154)$. Lymph node metastasis occurred in 25 cases, including no patients in group I, 11 in group II, and 14 in group III. The lymph node metastasis rates in the four groups in the current study were $0,0,7.5$, and $14.9 \%$, with an overall lymph node metastasis rate of $8.0 \%$ in the four groups. The total lymph node metastasis rates were similar to those found by Ding et al. [11] and Haruki et al. [12].

Lymphovascular invasion occurs when a small vein, artery, or lymphatic vessel wall in the tumor is damaged or there is a tumor thrombus in the lumen. The condition can be divided into vascular and lymphatic cancer thrombi, with a vascular tumor thrombus being a prerequisite for tumor invasion of the vascular system and lymph node metastasis. Lymphovascular invasion is believed to be a predictor of poor prognosis in patients with lung cancer. Tomoshi et al. showed that the 5-year overall survival rate of patients with vascular cancer thrombus was similar to that of stage IB patients without lymphovascular invasion [13]. It was therefore suggested that lymphovascular invasion should be considered as a factor in determining TNM stage. Furthermore, patients with phase IA lung cancer and lymphovascular invasion required postoperative oral uracil chemotherapy, which increased the 5-year survival rate from 66.6 to $93.3 \%$ [13].

Recent studies found that pathological type, pleural invasion, and CEA level were also important risk factors for lymph node metastasis $[14,15]$, as in the current study.

There is currently no clinical consensus on the need for segmental resection or lobectomy, and lymph node system cleaning or sampling in patients with early lung cancer. Both National Comprehensive Cancer Network and American College of Chest Physicians guidelines regard standard lobectomy and lymph node sampling/ dissection as the standard procedures for early resection of non-small cell lung cancer [16, 17]. However, some studies suggested that there was no difference in long-term survival rates between patients with early lung cancer undergoing sublobectomy and lobectomy for tumors $<2 \mathrm{~cm}$ in diameter [18]. The American College of Chest Physicians guidelines suggest that sublobectomy can also be performed for pure GGOs with a diameter $<2 \mathrm{~cm}$ [17]. Tsutani et al. showed that, for GGO-dominant T1b tumors, 3-year recurrence-free survival rates were similar in patients who underwent lobectomy (93.7\%), segmentectomy (92.9\%), and wedge resection $(100 \%)(P=0.66)[19]$.

It is currently difficult to predict the existence of lymph node metastasis before surgery for early clinical lung cancer. Regarding intraoperative lymph node management, the benefit of systematic lymph node cleaning over lymph node sampling remains unclear. The randomized controlled ACOSOG Z0030 trial found no differences in local and distant recurrence rates and survival rates between the two groups; however, systematic lymph node dissection allowed more accurate staging [20]. Moon et al. analyzed 358 patients with non-small cell lung cancers $\leq 3$ $\mathrm{cm}$ in diameter [21]. The postoperative pathology was adenocarcinoma in 129 patients with GGO-predominant findings, including only one case of lymph node metastasis, and there was no significant difference in 5-year recurrence rates between patients without lymph node dissection and those with lymph node dissection or sampling. The authors therefore suggested that no mediastinal lymph node dissection or sampling could reduce the operation risk and duration and thus improve the postoperative condition in lung cancer patients with GGO [21]. In the current study, no patients with PGGO or GGOdominated lung cancer had lymph node metastasis, consistent with the results of Ye et al. [22]. Ye et al. also considered that most PGGO nodules were adenocarcinoma in situ or minimally invasive and lymph node metastasis was rare, suggesting that lymph node dissection 
should not be performed during surgery. Jiang et al. published a consensus on the diagnosis and treatment of early pulmonary adenocarcinoma with ground glass nodules at Shanghai Lung Hospital, which also concluded that there was no need for lymph node cleaning or sampling during surgery for in situ and microinvasive adenocarcinoma [23].

This study had some limitations. First, it was a retrospective study, and second, it was conducted at a singlecenter with a relatively small number of cases. Further multicenter randomized trials are therefore needed to verify these results.

\section{Conclusions}

This study identified tumor diameter, solid component ratio, serum CEA level, pathological type, lymphovascular invasion, and pleural invasion as independent risk factors for lymph node metastasis in patients with clinical stage IA lung adenocarcinoma. Non-mediastinal lymph node metastasis is rare in patients with lung adenocarcinoma dominated by GGO component, and adenocarcinoma with PGGO may thus be treated by excision or lobectomy, with no need for mediastinal lymph node cleaning or sampling.

\section{Abbreviations}

GGO: Ground glass opacity; CEA: Plasma carcinoembryonic antigen; PGGO: Pure ground-glass opacity; AIS: Adenocarcinoma in situ; MIA: Minimally invasive; IA: Invasive adenocarcinoma

\section{Acknowledgements}

We thank Susan Furness, PhD, from Liwen Bianji, Edanz Editing China (www.liwenbianji.cn/ac), for editing the English text of a draft of this manuscript.

\section{Authors' contributions}

Lijun Jing and Yongming Wang contributed equally to this work. LJJ and YMW made substantial contributions to the conception and design of the work. GCW made substantial contributions to the acquisition, analysis, and interpretation of data for the work. All authors gave their final approval of the version to be published.

\section{Funding}

Not applicable.

\section{Availability of data and materials}

All data generated or analyzed during this study are included in this published article.

\section{Ethics approval and consent to participate}

This study was conducted in accordance with the declaration of Helsinki. This study was approved by the Ethics Committee of the Second People's Hospital of Weifang. Because this was a retrospective study, informed consent was waived.

\section{Consent for publication}

We have obtained consent to publish from the participants (or legal parent or guardian) to report their individual patient data.

\section{Competing interests}

The authors declare that they have no competing interests.

\section{Author details}

'Department of Thoracic Surgery, Shandong Provincial Hospital, Cheeloo College of Medicine, Shandong University, Jinan 250021, Shandong, China. ${ }^{2}$ Department of Thoracic Surgery, Weifang NO.2 People's Hospital, Yuanxiao Street, Kuiwen District, Weifang 261041, China. ${ }^{3}$ Department of Anesthesiology, Weifang NO.2 People's Hospital, Yuanxiao Street, Kuiwen District, Weifang 261041, China.

Received: 4 March 2020 Accepted: 18 May 2020

Published online: 12 August 2020

\section{References}

1. Torre LA, Siegel RL, Jemal A. Lung cancer statistics [J]. Adv Exp Med Biol. 2016;893:1-19.

2. Chheang S, Brown K. Lung Cancer staging: clinical and radiologic perspectives [J]. Semin Interv Radiol. 2013;30(2):99-113.

3. Okayama $H$, Kohno $T$, Ishii $Y$,et al. Identification of genes upregulated in ALK-positive and EGFR/KRAS/ALK-negative lungadenocarcinomas. Cancer Res. 2012;72(1):100-111. doi: 10.1158/0008-5472.CAN-11-1403. Epub 2011 Nov 11 .

4. Meza R, Meernik C, Jeon J, et al. Lung cancer incidence trends by gender, race and histology in the United States, 1973-2010. PLoS One. 2015;10(3): e0121323.

5. Rami-Porta R, Bolejack V, Crowley J, et al. The IASLC lung cancer staging project: proposals for the revisions of the $T$ descriptors in the forthcoming eighth edition of the TNM classification for lung cancer. J Thorac Oncol, 2015; 10(7): 990-1003.doi: 10.1097/JTO.0000000000000559.

6. Travis WD, Brambilla E, Noguchi M, et al. International Association for the Study of Lung Cancer/American Thoracic Society/European Respiratory Society international multidisciplinary classification of lung adenocarcinoma. J Thorac Oncol. 2011;6(2):244-85.

7. Yuancai $X$, Yun L, Yanguo L, et al. Primary Study on Mediastinal Lymph Node Metastasis in Patients with $\leq 3 \mathrm{~cm}$ Peripheral Non-small Cell Lung Cancer. Chin J Mininally Invasive Surg. 2010;10(7):577-80.

8. Okada M, Nishio W, Sakamoto T, et al. Effect of tumor size on prognosis in patients with non-small cell lung cancer: the role of segmentectomy as a type of lesser resection. Thorac Cardiovasc Surg. 2005;129(1):87-93.

9. Matsuguma H, Yokoi K, Anraku M, et al. Proportion of ground-glass opacity on high-resolution computed tomography in clinical T1NOMO adenocarcinoma of the lung. A predictor of lymph node metastasis. J Thorac Cardiovasc Surg. 2002;124(2):278-84.

10. Zha J, Dong X, Xie H, et al. Recognition of "aggressive" behavior in "indolent" ground glass opacity and mixed density lesions [J]. J Thorac Dis, 2016:8(7):1460-8.

11. Ding N, Mao Y, Gao S, et al. Predictors of lymph node metastasis and possible selective lymph node dissection in clinical stage IA non-small cell lung cancer [J]. J Thorac Dis. 2018;10(7):4061-8.

12. Haruki T, Aokage K, Miyoshi T, et al. Mediastinal nodal involvement in patients with clinical stage I non-small-cell lung cancer: possibility of rational lymph node dissection [J]. J Thorac Oncol. 2015;10(6):930-6.

13. Tomoshi T, Satoshi H, Shinji A, et al. Upstaging by vessel invasion improves the pathology staging system of non-small cell lung cancer. Chest. 2007; 132(1):170-7.

14. Fukui $T$, Katayama $T$, Ito $S$, et al. Clinicopathological features of small-sized non-small cell lung cancer with mediastinal lymph node metastasis. 2009; 66(3):309-13.[J]. Lung Cancer, 2009 Dec, 66(3): 309-313.

15. Kudo Y, Saji H, Shimada Y, et al. Impact of visceral pleural invasion on the survival of patients with non-small cell lung cancer [J]. Lung Cancer. 2012; 78(2):153-60.

16. Ettinger DS, Wood DE, Aisner DL, et al. Non-Small Cell Lung Cancer, Version 5.2017, NCCN Clinical Practice Guidelines in Oncology. J Natl Compr Canc Netw. 2017;15(4):504-35. https://doi.org/10.6004/jnccn.2017.0050.

17. Howington JA, Blum MG, Chang AC, et al. Treatment of stage I and II nonsmall cell lung cancer: diagnosis and management of lung cancer, 3rd ed: American College of Chest Physicians evidence-based clinical practice guidelines. Chest, 2013;143(5 Suppl): e278S-e313S. doi: 10.1378/ chest. 122359.

18. Altorki NK, Yip R, Hanaoka T, et al. Sublobar resection is equivalent to lobectomy for clinical stage 1a lung cancer in solid nodules. J Thorac Cardiovasc Surg, 2014, 147(2): 754-762; Discussion 762-754. doi:10.1016/j. jtcvs.2013.09.065. 
19. Tsutani $Y$, Miyata $Y$, Nakayama $H$, et al. Appropriate sublobar resection choice for ground glass opacity-dominant clinical stage la lung adenocarcinoma: wedge resection or segmentectomy. Chest. 2014;145(1): 66-71.

20. Darling GE, Allen MS, Decker PA, et al. Randomized trial of mediastinal lymph node sampling versus complete lymphadenectomy during pulmonary resection in the patient with N0 or N1 (less than hilar) non-small cell carcinoma: results of the American college of surgery oncology group Z0030 trial. J Thorac Cardiovasc Surg, 2011, 141(3): 662-670. doi:10.1016/ j. jtcvs.2010.11.008.

21. Moon $Y$, Sung SW, Namkoong M, et al. The effectiveness of mediastinal lymph node evaluation in a patient with ground glass opacity tumor. J Thorac Dis, 2016, 8(9): 2617-2625. doi: 10.21037/jtd.2016.08.75.

22. Ye $B$, Cheng $M, G e X X$, et al. Factors that predict lymph node status in clinical stage T1aNOMO lung adenocarcinomas. World J Surg Oncol2014 Feb 21;12:42. doi: 10.1186/1477-7819-12-42.

23. Jiang G, Chen C, Zhu Y, et al. Shanghai pulmonary hospital experts consensus on the Management of Ground-Glass Nodules Suspected as lung adenocarcinoma (version 1). Zhongguo Fei Ai Za Zhi2018; 21(3):147-159. doi: 10.3779/j.issn. 1009- 3419. 2018.03.05.

\section{Publisher's Note}

Springer Nature remains neutral with regard to jurisdictional claims in published maps and institutional affiliations.

Ready to submit your research? Choose BMC and benefit from:

- fast, convenient online submission

- thorough peer review by experienced researchers in your field

- rapid publication on acceptance

- support for research data, including large and complex data types

- gold Open Access which fosters wider collaboration and increased citations

- maximum visibility for your research: over $100 \mathrm{M}$ website views per year

At BMC, research is always in progress.

Learn more biomedcentral.com/submissions 